\section{Achievement Goals}

\author{
Nicolas Sommet ${ }^{1,2}$ and Andrew J. Elliot ${ }^{1}$ \\ ${ }^{1}$ Department of Clinical and Social Sciences in \\ Psychology, University of Rochester, Rochester, \\ NY, USA \\ ${ }^{2}$ Life Course and Inequality Research Centre, \\ University of Lausanne, Lausanne, Switzerland
}

\section{Synonyms}

Goal orientations; Goal standards

\section{Definition}

Achievement goals are self-regulatory commitments that provide direction to individuals as they interpret and respond to competence-relevant situations. Four types of achievement goals have been the primary focus of the literature: Masteryapproach goals (master a task; improve over time), performance-approach goals (outperform others), mastery-avoidance goals (not fall short of mastering a task; not decline over time), and performance-avoidance goals (not be outperformed by others).

\section{Introduction}

\section{Achievement Goal Conceptualizations}

The first generation of achievement goals research was based on a dichotomous framework (e.g., Dweck 1986). Two types of goals were distinguished: mastery goals and performance goals. Mastery goals were defined in terms of developing competence and task mastery and performance goals in terms of demonstrating competence relative to others. This distinction can be understood in terms of the definition of one's competence (Elliot 1999): To assess competence, mastery-focused individuals use a taskreferenced standard (meeting vs. not meeting a task requirement) or a self-referenced standard (progressing vs. stagnating or declining over time), whereas performance-focused individuals use another referenced standard (outperforming vs. being outperformed by others).

The second generation of achievement goal research was based on a trichotomous and, ultimately, a $2 \times 2$ framework (Elliot 1999). Based on both a conceptual analysis and recurring empirical inconsistencies, scholars proposed that mastery and performance goals could take two forms: an approach form and an avoidance form. In their approach form, achievement goals focus on the attainment of desirable ends (i.e., approaching success), whereas in their avoidance form, they focus on the prevention of undesirable ends (i.e., avoiding failure). This distinction refers to the valence of competence: On the one hand, 


\section{Definition}

\begin{tabular}{|c|c|c|}
\hline & $\begin{array}{l}\text { Task- / Self- } \\
\text { referenced standard }\end{array}$ & $\begin{array}{l}\text { Other- } \\
\text { referenced standard }\end{array}$ \\
\hline $\begin{array}{c}\text { Positive } \\
\text { (approaching } \\
\text { success) }\end{array}$ & $\begin{array}{c}\text { Mastery-approach goals } \\
\text { (master a task; } \\
\text { improve over time) }\end{array}$ & $\begin{array}{c}\text { Performance-approach goals } \\
\text { (outperform others) }\end{array}$ \\
\hline $\begin{array}{l}\text { Negative } \\
\text { (avoiding } \\
\text { failure) }\end{array}$ & $\begin{array}{l}\text { Mastery-avoidance goals } \\
\text { (not fall short of mastering a } \\
\text { task; not decline over time) }\end{array}$ & $\begin{array}{l}\text { Performance-avoidance goals } \\
\text { (not be outperformed by others) }\end{array}$ \\
\hline
\end{tabular}

Achievement Goals, Fig. $12 \times 2$ achievement goal framework (Adapted from Elliot and McGregor 2001). Definition and valence correspond to the two dimensions of competence: task-/self- and other referenced standard

those endorsing mastery-approach goals are centered on reaching task- or self-referential competence and those endorsing mastery-avoidance goals on avoiding task- or self-referential incompetence; on the other hand, performance-approach focused individuals are centered on reaching normative competence and performance-avoidance focused individuals on avoiding normative incompetence (see Fig. 1).

Two other conceptual developments may be noted. First, a $3 \times 2$ achievement goal framework has been posited (Elliot et al. 2011) in which the mastery goal construct is bifurcated in terms of task-based goals and self-based goals. Task-based goals use the absolute demands of the task as the standard of competence evaluation (trying to do well or avoid doing poorly relative to what task requires), whereas self-based goals use one's intrapersonal trajectory as the competence standard (trying to do well or avoid doing poorly relative to how one did before).

Second, achievement goal theorists have proposed a separation of the aim (i.e., goal) component (pertaining to the direction of behavior) from the reasons underlying the aim (pertaining to the energization of behavior), leading to the concept of goal complex (for a review, see Vansteenkiste et al. 2014). A goal complex consists of a specific refer to the two main ways that competence can be defined. Positive and negative refer to the two ways that competence can be valenced

combination of goal and reason. For instance, one can pursue a performance-approach goal for an autonomous reason, such as striving to do better than others in order to experience the thrill of competition. Conversely, one can pursue a performance-approach goal for a controlled reason, such as striving to do better than others in order to show one's peers that one is worthy of love and acceptance.

\section{Consequences of Achievement Goals}

Commonly relying on the trichotomous and $2 \times 2$ achievement goal frameworks, scholars over the years have examined the consequences of achievement goals on cognitive, emotional, attitudinal, and behavioral outcomes (for reviews, see Senko et al. 2011; Wirthwein et al. 2013). Masteryapproach goals tend to be most strongly associated with interest-driven processes and outcomes, predicting deep learning strategies, positive activity emotions (e.g., enjoyment), intrinsic motivation, and a reciprocity orientation toward information exchange while often being unrelated to achievement. Performance-approach goals tend to be most strongly associated with outcome-driven processes and outcomes, predicting surface learning strategies, positive outcome emotions (e.g., pride), grade aspirations, and cheating behaviors while 
often being positively related to achievement. Since achievement goals are conceptually orthogonal, endorsing the two goals jointly could be adaptive on the whole, with individuals reaping the benefits of mastery-approach goals in terms of interest, as well as those of performance-approach goals in terms of achievement. In contrast, performance-avoidance goals tend to be most strongly associated with maladaptive processes and outcomes, such as self-handicapping and study disorganization, negative outcome emotions (e.g., test anxiety), dropout behavior, and often poor achievement. Although less investigated, mastery-avoidance goals also seem to produce adverse processes and outcomes, such as maladaptive perfectionism, negative activity emotions (e.g., task anxiety), procrastination, and in some instances poor achievement.

Preliminary empirical evidence suggests that one subcomponent of mastery-approach goals, task-approach goals, seems to facilitate learning processes to a greater extent than the other subcomponent of mastery-approach goals, selfapproach goals, positively predicting task absorption, self-efficacy, and intrinsic motivation. In addition, self-avoidance goals might impair learning processes to a greater extent than taskavoidance goals, although more research is needed on these subcomponents before strong statements are warranted. Finally, research on goal complexes seems to indicate that masteryand performance-approach goals are especially beneficial for learning experiences and achievement when associated with autonomous rather than controlling reasons (e.g., when the goal is pursued for the joy or the challenge it provides; see Vansteenkiste et al. 2014).

\section{Antecedents of Achievement Goals}

Achievement goals can be conceptualized as both general tendencies that are rather stable over time and temporary states that vary with the achievement situation. The pursuit of achievement goals is influenced by a number of dispositional antecedents, such as achievement motives, temperaments, attachments styles, implicit theory of intelligence, and perceptions of ability. In addition, various environmental factors can influence achievement goal pursuit (see Elliot 1999; Lochbaum et al. in press).

One example of an environmental antecedent of personal achievement goals is the achievement goal structure emphasized in the competencerelevant context. On the one hand, when supervisors (teachers, managers, coaches, etc.) or institutions (universities, organizations, sport clubs, etc.) reward effort rather than outcomes, rely on private or criterion-referenced assessments or use autonomy-supportive practices, they create mastery goal structures that encourage the pursuit of mastery-based goals. On the other hand, when supervisors or institutions reward outcomes rather than effort, rely on public or norm-referenced assessments, or use controlling practices, they create performance goal structures that encourage the endorsement of performance-based goals (Sommet et al. 2015).

\section{Achievement Goal Operationalization}

The Patterns of Adaptive Learning Scale (PALS; Midgely et al. 2000) and the Achievement Goal Questionnaire-Revised (AGQ-R; Elliot and Murayama 2008) are the most frequently used tools to measure achievement goals. The AGQ-R is different from many other achievement goal assessments in that it explicitly targets the standard of competence per se as the core of goal content (i.e., task- and self-competence/incompetence for mastery-based goals and normative competence/ incompetence for performance-based goals) and keeps other, more general, motivational concepts such as desires/fears, emotions, and relational concerns out of the goal itself. In the AGQ-R, three items assess mastery-approach goals (e.g., "My goal is to learn as much as possible"), three assess mastery-avoidance goals (e.g., "My aim is to avoid learning less than I possibly could"), three assess performance-approach goals (e.g., "My goal is to perform better than the other students"), and three assess performance-avoidance goals (e.g., "My aim is to avoid doing worse than other students"). It should be noted that using this questionnaire has limitations that are in need of further attention. In particular, performance-approach and performanceavoidance goals are often moderately to strongly correlated in the measure. Additional research is 
needed to understand why and when this correlation is strong and the implications of this for both empirical patterns and understanding daily approach- and avoidance-based regulation.

\section{Conclusion}

Achievement goals are central constructs in the achievement motivation literature that emphasize the differentiated nature of competence pursuits in achievement situations. The achievement goal literature has consistently developed, both conceptually and empirically, over the past four decades, and research in this area has led to a deeper and clearer understanding of how individuals adopt and pursue goals in school, sport, and work settings. Much has been learned to date, but much remains to be learned as well. In particular, as achievement goals do not emerge from a motivational vacuum (i.e., an achievement goals are necessarily endorsed for some reason or set of reasons), the study of achievement goal complexes holds great promise for a more complete understanding of competence motivation.

\section{Cross-References}

\author{
- Achievement Motives \\ - Approach-Avoidance Competition \\ - Implicit Theories of Intelligence \\ - Intrinsic/Extrinsic Motivation \\ - Mastery Goals \\ $\checkmark$ Perfectionism \\ - Self-Efficacy \\ - Self-Handicapping \\ - Social Comparison Theory
}

\section{References}

Dweck, C. S. (1986). Motivational processes affecting learning. American Psychologist, 41, 1040-1048.

Elliot, A. J. (1999). Approach and avoidance motivation and achievement goals. Educational Psychologist, 34, 169-189.

Elliot, A. J., \& McGregor, H. A. (2001). A $2 \times 2$ achievement goal framework. Journal of Personality and Social Psychology, 80, 501-519.

Elliot, A. J., \& Murayama, K. (2008). On the measurement of achievement goals: Critique, illustration, and application. Journal of Educational Psychology, 100, 613-628.

Elliot, A. J., Murayama, K., \& Pekrun, R. (2011). A $3 \times 2$ achievement goal model. Journal of Educational Psychology, 103, 632-648.

Lochbaum, M., Jean-Noel, J., Pinar, C., \& Gilson, T. (in press). A meta-analytic review of Elliot's (1999) Hierarchical Model of Approach and Avoidance Motivation in the sport, physical activity, and physical education literature. Journal of Sport and Health Science. http://www.sciencedirect.com/science/article/pii/ S2095254615001234

Midgely, C., Maeher, M. L., Hruda, L. Z., Anderman, E., Anderman, L., Freeman, K. E., Gheen, M., Kaplan, A., Kumar, R., Middleton, M. J., Nelson, J., Roeser, R., \& Urdan, T. (2000). Manual for the patterns of adaptive learning scales. Ann Arbor: University of Michigan.

Senko, C., Hulleman, C. S., \& Harackiewicz, J. M. (2011). Achievement goal theory at the crossroads: Old controversies, current challenges, and new directions. $E d u$ cational Psychologist, 46, 26-47.

Sommet, N., Quiamzade, A., Jury, M., \& Mugny, G. (2015). The student-institution fit at university: Interactive effects of academic competition and social class on achievement goals. Frontiers in Psychology| Educational Psychology, 6, 769.

Vansteenkiste, M., Lens, W., Elliot, A. J., Soenens, B., \& Mouratidis, A. (2014). Moving the achievement goal approach one step forward: Toward a systematic examination of the autonomous and controlled reasons underlying achievement goals. Educational Psychologist, 49, 153-174.

Wirthwein, L., Sparfeldt, J. R., Pinquart, M., Wegerer, J., \& Steinmayr, R. (2013). Achievement goals and academic achievement: A closer look at moderating factors. Educational Research Review, 10, 66-89. 